\title{
Lung Biopsy in Interstitial Lung Diseases: There Is More than One Way to Cook an Egg
}

\author{
Mouhamad Nasser $^{a} \quad$ Vincent Cottin $^{a, b}$ \\ a Department of Respiratory Medicine, National Reference Center for Rare Pulmonary Diseases, Hospices Civils de \\ Lyon, Lyon, France; b UMR754, INRA, Claude Bernard University Lyon 1, University of Lyon, Lyon, France
}

Interstitial lung diseases (ILDs) encompass a large group of rare pulmonary diseases, which were all described as clinical, radiological, and pathological entities. Although multidisciplinary discussion has replaced pathology as the gold standard, especially regarding idiopathic pulmonary fibrosis (IPF), in many cases pathology remains crucial. Even in IPF, despite progress made in radiological diagnosis [1], a pattern of usual interstitial pneumonia on high-resolution computed tomography (HRCT) of the chest, which allows a noninvasive diagnosis of IPF in the appropriate context, is present in less than half of the cases, while in all other cases a biopsy should be contemplated [2]. In conditions other than IPF, radiological interobserver agreement is often poor, and a noninvasive diagnosis is even more difficult, especially in nonspecific interstitial pneumonia and chronic hypersensitivity pneumonitis [3]. Despite the involvement of different specialists in discussing complex cases at multidisciplinary meetings, at least $10 \%$ of ILD cases remain unclassifiable [4-7]. This "category" of unclassifiable ILD should be reduced to a minimum whenever possible, and every effort should be made to propose a most likely diagnosis in order to better inform management decisions.

The need to obtain a confident diagnosis - with practical implications for any indication for therapy, especially

\section{KARGER}

(c) 2018 S. Karger AG, Basel

E-Mail karger@karger.com

www.karger.com/res regarding IPF - contrasts with the small number of surgical lung biopsies performed. It was recently estimated that only $5 \%$ of clinically suspected IPFs were biopsied [8]. The risk of surgical lung biopsy, which low for patients younger than 65 years and with no significant comorbidity and preserved lung function who are referred for elective surgery, is higher in other situations $[9,10]$, and a biopsy may be impracticable or risky. In addition, physicians often are reluctant to refer patients for lung biopsy even in the absence of any contraindication or comorbidity, and most patients would generally prefer not to undergo surgery.

Over recent years, this need to balance diagnostic uncertainty with the risk of biopsy [9] has generated some pressure to develop newer techniques (including genomics, genetics, biomarkers, and new imaging techniques) in order to move away from lung biopsy and also to assess the diagnostic accuracy of less invasive techniques of accessing lung tissue. Recently, transbronchial lung cryobiopsy has been shown to be a valuable tool for the pathological assessment of ILDs [11-14]. With more experience available, the risks of and contraindications to cryobiopsy are now better known, and the procedure is becoming more standardized [15]. Conventionally, forceps transbronchial lung biopsies are not recommended 
in the diagnostic algorithm of ILDs, due to limitations caused by the inadequacy and restricted size of the pathologic specimen; however, they might prove useful in certain circumstances $[16,17]$.

Indeed, the sample size is the main limitation to any contribution of endoscopic methods of lung biopsy to the diagnostic algorithm. The optimal size of a lung biopsy specimen has not been established; however, the bigger the tissue specimen, the higher the yield and the lower the risk of sampling error. Interpretation by pathologists is easier with large and multiple surgical lobe biopsies, as recommended [18]. Also, large-sized biopsies from different zones may show multiple pathological patterns, and management should be adapted according to the pattern associated with the worst prognostic [19]. Larger biopsies are unquestionably needed when HRCT and pathologic patterns differ [18]. However, transbronchial lung cryobiopsy may have a meaningful impact on diagnostic confidence in the multidisciplinary diagnosis of ILDs, possibly contributing as much as does surgical lung biopsy to the diagnostic approach [14]. This clearly demonstrates that smaller samples may prove useful in the diagnosis of IPF and other ILDs despite the fact that the pathologist is likely to be less confident in the interpretation of available samples than when a surgical lung biopsy has been obtained.

In this issue of Respiration, Padrão et al. [20] report their experience of percutaneous CT-guided transthoracic lung biopsy (CT-TLB) in patients with ILDs. This technique has been previously used in ILD, but the experience and literature are still limited [21-24]. Among 169 consecutive patients, a definitive or probable diagnosis was obtained in $66 \%$ of the cases. Sufficient histological tissue, defined by the authors as a specimen of at least $10-20 \mathrm{~mm}$ in length and at least $1 \mathrm{~mm}$ in width, was obtained in $92.9 \%$ of the cases. The fact that CT-TLB was sometimes not diagnostic despite the fact that the samples were of the expected size directly reflects the limitation of the technique in sampling the lung. As seen with other diagnostic modalities, further issues may be related to disease complexity, the learning curve, or preparation of the specimens. The technique was particularly useful for patients with a consolidation or nodular pattern on HRCT, with a definitive/probable diagnosis obtained in 87.7 and $77.3 \%$ of the cases, respectively. Not surprisingly, organizing pneumonia was the most frequent diagnosis made (36.2\%). As previously suggested [25], CT-TLB may be particularly contributive in patients presenting with a consolidation pattern and suspicion of organizing pneumonia [26]. It is, in fact, acknowledged by the authors that this technique has been used preferentially over surgery or endoscopic techniques in subjects with consolidation or a nodular pattern, and the series by Padrão et al. [20] is therefore not representative of all-comers with ILD.

Importantly, no acute exacerbation of the underlying ILD occurred, even if postprocedural air embolism caused the death of 1 patient. Complications were more frequent among patients with a lower diffusing capacity of the lung for carbon monoxide. The most common complications were pneumothorax (17.8\%), hemoptysis (7.7\%), and hemothorax $(1.2 \%)$, comparable to previous reports [27, 28]. CT-TLB can be performed on the majority of patients, but those with altered mental status, intractable cough, invasive or noninvasive mechanical ventilation, severe ILD or emphysema, or bleeding diathesis are not eligible.

Interestingly, the average size of the specimens obtained by CT-TLB was $\sim 20 \mathrm{~mm}^{3}$, comparable to those obtained by transbronchial lung cryobiopsy and intermediate between those obtained by forceps transbronchial lung biopsy $\left(\sim 6 \mathrm{~mm}^{3}\right)$ and those obtained by surgical lung biopsy (a few cubic centimeters). The most important advantage of CT-TLB is that the lungs are under direct HRCT visualization, allowing for the targeting of focal or patchy opacities.

Many questions remain with regard to the use of CTTLB in patients with ILDs - for example: how does it compare to other nonsurgical biopsy modalities, especially cryobiopsy, and to surgical lung biopsy? Is this technique really helpful in situations other than consolidation on imaging, for example, those with an unclassifiable, nonspecific reticular pattern? What are the tolerance, safety, and diagnostic yield in subjects with associated cysts or emphysema?

Although this technique may certainly not be applied to all cases of ILD, it needs to be included in the armamentarium of techniques available for sampling lung tissue when deemed indicated. Until the distant day by which all available techniques will have been compared, the available methods for sampling lung tissue (surgical and nonsurgical) should be discussed in multidisciplinary meetings and the most appropriate method be chosen. In the coming era of personalized medicine, tailoring the diagnostic approach to the individual patient and their disease has never been more important.

\section{Disclosure Statement}

The authors declare no conflict of interest with regard to this editorial comment. 


\section{References}

1 Lynch DA, Sverzellati N, Travis WD, Brown KK, Colby TV, Galvin JR, et al: Diagnostic criteria for idiopathic pulmonary fibrosis: a Fleischner Society White Paper. Lancet Respir Med 2018;6:138-153.

2 Raghu G, Collard HR, Egan JJ, Martinez FJ, Behr J, Brown KK, et al; ATS/ERS/JRS/ALAT Committee on Idiopathic Pulmonary Fibrosis: An official ATS/ERS/JRS/ALAT statement: idiopathic pulmonary fibrosis: evidence-based guidelines for diagnosis and management. Am J Respir Crit Care Med 2011;183:788-824.

3 Walsh SLF, Wells AU, Desai SR, Poletti V, Piciucchi S, Dubini A, et al: Multicentre evaluation of multidisciplinary team meeting agreement on diagnosis in diffuse parenchymal lung disease: a case-cohort study. Lancet Respir Med 2016;4:557-565.

4 Ahmad K, Barba T, Gamondes D, Ginoux M, Khouatra C, Spagnolo P, et al: Interstitial pneumonia with autoimmune features: clinical, radiologic, and histological characteristics and outcome in a series of 57 patients. Respir Med 2017;123:56-62.

5 De Sadeleer LJ, Meert C, Yserbyt J, Slabbynck $\mathrm{H}$, Verschakelen JA, Verbeken EK, et al: Diagnostic ability of a dynamic multidisciplinary discussion in interstitial lung diseases: a retrospective observational study of 938 cases. Chest 2018;153:1416-1423.

6 Ryerson CJ, Urbania TH, Richeldi L, Mooney JJ, Lee JS, Jones KD, et al: Prevalence and prognosis of unclassifiable interstitial lung disease. Eur Respir J 2013;42:750-757.

7 Troy L, Glaspole I, Goh N, Zappala C, Hopkins P, Wilsher M, et al: Prevalence and prognosis of unclassifiable interstitial lung disease. Eur Respir J 2014;43:1529-1530.

8 Hopkins RB, Burke N, Fell C, Dion G, Kolb M: Epidemiology and survival of idiopathic pulmonary fibrosis from national data in Canada. Eur Respir J 2016;48:187-195.

9 Cottin V: Lung biopsy in interstitial lung disease: balancing the risk of surgery and diagnostic uncertainty. Eur Respir J 2016;48 1274-1277.

10 Hutchinson JP, McKeever TM, Fogarty AW, Navaratnam V, Hubbard RB: Surgical lung biopsy for the diagnosis of interstitial lung disease in England: 1997-2008. Eur Respir J 2016;48:1453-1461.

11 Dhooria S, Sehgal IS, Aggarwal AN, Behera D, Agarwal R: Diagnostic yield and safety of cryoprobe transbronchial lung biopsy in diffuse parenchymal lung diseases: systematic review and meta-analysis. Respir Care 2016; 61:700-712.

12 Marçôa R, Linhas R, Apolinário D, Campainha S, Oliveira A, Nogueira C, et al: Diagnostic yield of transbronchial lung cryobiopsy in interstitial lung diseases. Rev Port Pneumol (2006) 2017;23:296-298

13 Ravaglia C, Wells AU, Tomassetti S, Dubini A, Cavazza A, Piciucchi S, et al: Transbronchial lung cryobiopsy in diffuse parenchymal lung disease: comparison between biopsy from 1 segment and biopsy from $2 \mathrm{seg}$ ments - diagnostic yield and complications. Respiration 2017;93:285-292.

14 Tomassetti S, Wells AU, Costabel U, Cavazza A, Colby TV, Rossi G, et al: Bronchoscopic lung cryobiopsy increases diagnostic confidence in the multidisciplinary diagnosis of idiopathic pulmonary fibrosis. Am J Respir Crit Care Med 2016;193:745-752.

15 Colella S, Haentschel M, Shah P, Poletti V, Hetzel J: Transbronchial lung cryobiopsy in interstitial lung diseases: best practice. Respiration 2018;95:383-391.

16 Berbescu EA, Katzenstein AL, Snow JL, Zisman DA: Transbronchial biopsy in usual interstitial pneumonia. Chest 2006;129:11261131.

17 Sheth JS, Belperio JA, Fishbein MC, Kazerooni EA, Lagstein A, Murray S, et al: Utility of transbronchial vs surgical lung biopsy in the diagnosis of suspected fibrotic interstitial lung disease. Chest 2017;151:389-399.

18 Travis WD, Costabel U, Hansell DM, King TE Jr, Lynch DA, Nicholson AG, et al: An official American Thoracic Society/European Respiratory Society statement: update of the international multidisciplinary classification of the idiopathic interstitial pneumonias. Am J Respir Crit Care Med 2013;188:733-748.

19 Monaghan H, Wells AU, Colby TV, Du Bois RM, Hansell DM, Nicholson AG: Prognostic implications of histologic patterns in multiple surgical lung biopsies from patients with idiopathic interstitial pneumonias. Chest 2004; $125: 522-526$

20 Padrão E, Rodrigues M, Guimarães S, Caetano Mota P, Melo N, Souto Moura C, et al: Diagnostic yield of computed tomographyguided transthoracic lung biopsy in diffuse lung diseases. Respiration 2018, DOI: $10.1159 / 000489934$

21 Klose KC, Biesterfeld S, Böcking A: Percutaneous CT-controlled cutting-needle biopsy of diffuse interstitial and alveolar lung diseases - the technique and results (in German). Rofo 1992;157:26-33.

22 Lohela P, Tikkakoski T, Ämmälä K, Strengell L, Suramo I, Repo U: Diagnosis of diffuse lung disease by cutting needle biopsy. Acta Radiol 1994;35:251-254.

23 Oliveira M, Pereira T, Dias M, Sanches A, Campainha S, Neves S: Study of CT-guided core needle biopsy in patients with interstitial lung diseases: diagnostic yield and complications. Rev Port Pneumol (2006) 2016;22:353354.

24 Peng M, Xu W, Shi J, Cai B, Tian X, Liu T, et al: The diagnostic value of CT-guided percutaneous needle lung biopsy in diffuse parenchymal lung diseases (in Chinese). Zhonghua Jie He He Hu Xi Za Zhi 2012;35: 171-175.

25 Metzger F, Pernet D, Manzoni P, Ranfaing E, Dalphin JC: Apport de la biopsie pulmonaire transthoracique dans le diagnostic de pneumonie organisée. Rev Mal Respir 2008;25: 539-550.

26 Cottin V: Progrès pour le diagnostic de la pneumopathie organisée. Rev Mal Respir 2008;25:523-525.

27 Aktaș AR, Gözlek E, Yılmaz Ö, Kayan M, Ünlü N, Demirtaş H, et al: CT-guided transthoracic biopsy: histopathologic results and complication rates. Diagn Interv Radiol 2015, 21:67-70.

28 Schulze R, Seebacher G, Enderes B, Kugler G, Fischer J, Graeter T: Complications in CTguided, semi-automatic coaxial core biopsy of potentially malignant pulmonary lesions. Rofo 2015;187:697-702. 